\title{
A CONSTITUCIONALIDADE DO DIREITO AO ESQUECIMENTO À LUZ DA TEORIA INTERPRETATIVA DE RONALD DWORKIN
}

\author{
Nayana Guimarães Souza de Oliveira Poreli Bueno* \\ Fabricio Carlos Zanin ${ }^{1}$
}

\section{RESUMO}

A pesquisa aborda o conceito e a constitucionalidade do direito ao esquecimento, ante a ausência de consenso sobre o tema. O objetivo geral é analisar o problema da constitucionalidade desse direito à luz da teoria interpretativa de Ronald Dworkin. Ao final da pesquisa, concluiu-se que esse direito só pode ser entendido como constitucional se identificado com controle de dados pessoais, não cabendo entendê-lo como o direito de excluir ou desindexar informações de interesse público em razão da passagem do tempo. Tal interpretação subjuga os direitos à memória, à informação e à liberdade de expressão ao subjetivismo do intérprete.

Palavras-chave: Ronald Dworkin; Direito ao esquecimento; Direito à memória; Liberdade de expressão.

\section{THE CONSTITUTIONALITY OF THE RIGHT TO BE FORGOTTEN IN THE LIGHT OF RONALD DWORKIN'S INTERPRETATIVE THEORY}

\begin{abstract}
The research addresses the concept and constitutionality of the right to be forgotten, given the absence of consensus on the topic. The objective is to analyse the problem in the light of Ronald Dworkin's interpretative theory. It was concluded that this right can only be understood as constitutional if identified with the control of personal data, and it's not appropriate to understand it as the right to exclude or deindex information of public interest due to the passage of time. Such an interpretation subordinates the rights to memory, information and freedom of expression to the subjectivism of the interpreter.
\end{abstract}

Keywords: Ronald Dworkin; Right to be forgotten; Right to memory; Freedom of expression.

\section{INTRODUÇÃO}

\footnotetext{
* Doutoranda em Direito Constitucional pela PUC-Rio. Mestre em Direito pela UFG. Assessora Jurídica no Tribunal de Justiça do Tocantins. E-mail: nayana_guimaraes@yahoo.com.br.

${ }^{1}$ Professor Efetivo da Universidade Federal do Tocantins - UFT. Mestre em Direito na Universidade do Vale do Rio dos Sinos - UNISINOS. Doutorando em Direito na Universidade Federal do Pará - UFPA. http://lattes.cnpq.br/3258935280144372. E-mail: professorzanin @uft.edu.br
} 
Há importantes disputas doutrinárias sobre o que se pode entender por direito ao esquecimento. Neste artigo, busca-se estudar o conceito e a constitucionalidade desse direito, no ordenamento jurídico brasileiro, à luz da teoria interpretativa de Ronald Dworkin. Para tanto, a metodologia adotada será a análise hermenêutica do problema, aplicável às ciências do espírito. Compreender é buscar um conhecimento empático do outro, é mover-se no terreno da intersubjetividade, deixando-se guiar pelo texto, buscando a sua melhor compreensão (COELHO, 2015, p. 87). A abordagem será qualitativa, incluída a subjetividade do pesquisador como componente da pesquisa.

O texto será dividido em três partes. Na primeira, estudar-se-á a teoria interpretativa de Ronald Dworkin. Na segunda parte, será feito um esforço conceitual acerca do direito ao esquecimento. Por fim, será desenvolvida uma interpretação acerca da constitucionalidade do direito ao esquecimento, tendo como norte a teoria interpretativa de Dworkin.

\section{A TEORIA INTERPRETATIVA DE RONALD DWORKIN}

A teoria do direito, para Ronald Dworkin - um dos principais filósofos do direito do século XX - procura responder à pergunta sobre em que condições as pessoas têm um direito jurídico. Se enquadra no campo da teoria política, pois o conteúdo do direito é determinado a partir de uma discussão política sobre os direitos e deveres dos cidadãos (LUZ, 2016), assim, não é possível desenvolvê-la sem conectar moral, ética, política e direito, sem falar de valores.

O pensamento político de Dworkin é chamado de igualitarismo liberal. É liberal porque, nessa tradição, o Estado deve ser neutro quanto às concepções de vida digna que cada cidadão tem, e garantir condições mínimas que realizem seus projetos de vida. É igualitário porque o princípio da igualdade de tratamento é o primeiro princípio de justiça: todos devem ser considerados, pelo Estado, com igual respeito e consideração. No entanto, a igualdade não conflita com as liberdades básicas, pois bem-social e direitos individuais não se opõem, já que ambos estão fundados na ideia de igualdade (DALL'AGNOL, 2005, p. 58-59).

Enquanto o Estado deve respeitar a concepção de vida digna que cada pessoa tem, cabe aos indivíduos assumirem responsabilidade quanto a seus atos e decisões. A dignidade humana observa dois princípios: o do valor intrínseco, segundo o qual toda vida humana 
possui valor objetivo; e o da responsabilidade pessoal, segundo o qual cada ser humano é moralmente responsável pelas escolhas que faz (FADEI; VERBICARO, 2018, p. 261-266).

À luz da teoria política do igualitarismo liberal, Ronald Dworkin (2010, p. VIII-IX) concebe uma teoria da decisão judicial como parte da teoria geral do direito que busca compreender que padrões os juízes devem utilizar para decidir casos difíceis. Sua teoria, porém, se diferencia de outras teorias liberais - o positivismo jurídico e o utilitarismo.

Discorda do positivismo jurídico porque propõe que o juiz, nos casos difíceis (em que não há regra explícita), decide discricionariamente, e dessa maneira cria o direito e o aplica ex post facto. Para Dworkin, essa teoria é equivocada porque os indivíduos podem ter direitos contra o Estado, anteriores aos criados por lei; esses, todavia, não são os direitos naturais, mas são extraídos das tradições morais da comunidade. Para o positivismo, o direito é um modelo de regras; já para Dworkin, a justificação das decisões judiciais é baseada em regras e em princípios jurídicos. A aplicação das regras se faz à maneira "tudo-ou-nada": ou uma regra é válida conforme uma outra regra de reconhecimento que atesta seu pedigree, e, assim, é aplicável, ou não é válida nem aplicável. Por sua vez, a aplicação de princípios ocorre por meio da análise do seu peso ou importância em determinado caso.

Dworkin (2010, p. 36) discorda das teorias utilitaristas porque defende que os juízes devem decidir os casos difíceis analisando argumentos de princípio, e não políticos. Padrões de política são aqueles que estipulam um objetivo de melhoria econômica, política ou social da comunidade; já princípios são padrões que promovem a justiça ou a equidade. Os juízes não podem tomar decisões com base em metas sociais: apenas as decisões fundamentadas em princípios podem ser tomadas pelos juízes (VERBICARO; FADEI, 2018, p. 254).

Os princípios revelam uma intencionalidade moral do direito que, todavia, deve ser fruto de interpretação, pois não é evidente. Isto é, embora os princípios possuam conceitos controversos, é possível argumentar em torno de sua conceituação e sua importância considerando-se outros princípios e práticas. Dworkin concebe uma estrutura argumentativa em que um princípio do ordenamento jurídico deve ser apoiado em outros princípios e práticas do mesmo ordenamento (DWORKIN, 2010, p. 65-66). Sua teoria tem como base a integridade (teoria da unidade do valor): os agentes públicos devem "se orientar por um padrão coerente de princípios" (JUNG, 2016, p. 126). Quando considerados todos os 
princípios e sua importância, já não se pode falar em decisão discricionária (DWORKIN, 2010, p. 57).

Para o autor, a obrigação jurídica existirá toda vez que as razões que sustentam a sua existência, em termos de princípios jurídicos, sejam mais fortes que as razões que pesam contra a sua existência (DWORKIN, 2010, p. 71). Mas isso não ocorre por meio de um "sopesamento" de bens e valores, mas por meio de uma interpretação criativa que "volta-se para a identificação dos propósitos que tornam o objeto o melhor possível diante do que se acredita, como intérprete, que ele deveria ser" (THEDORO FILHO, 2015, p. 661).

Para interpretar bem, os juristas podem imaginar-se como autores de um romance que deve ser escrito em cadeia por várias pessoas. Ao escreverem um capítulo desse romance, não podem contradizer os anteriores nem os tornar incoerente. Quando identificam um "erro" nos capítulos anteriores, devem justificar o porquê de modificarem a "história" em um caso concreto (DWORKIN, 2005, p. 238-240). A interpretação criativa que Dworkin propõe se volta para os propósitos do texto legal e constitucional, para a sua intencionalidade moral. Para tanto, é preciso observar o texto canônico da obra analisada, não se podendo extrapolálo; assim como se interpreta uma obra de arte, sem modificá-la, o texto jurídico deve ser interpretado à luz de sua melhor finalidade (THEODORO FILHO, 2016, 660-662).

Desse modo, interpretar a lei e a Constituição é atribuir-lhes valor. Semelhantemente ao que ocorre na interpretação literária, os propósitos atribuídos ao texto jurídico devem ser razões públicas, intenções comunitárias nas quais se firma a prática social, e não as intenções individuais dos participantes dessa prática (THEODORO FILHO, 2016, p. 662-663).

Vistos os principais aspectos da teoria da decisão de Ronald Dworkin, necessário se faz um esforço conceitual, no tópico seguinte, acerca do direito ao esquecimento com o intuito de conduzir a pesquisa no sentido de uma possível resposta adequada ao problema da sua constitucionalidade.

\section{O DIREITO AO ESQUECIMENTO: UM ESFORÇO CONCEITUAL}

A revisão bibliográfica sobre o direito ao esquecimento demonstra que não há um consenso sobre a sua existência, extensão e fundamento constitucional. Há quem o intérprete como um direito fundamental implícito decorrente do direito à privacidade (LUCENA, 2018, 
p. 30); por outro lado, há quem o relacione com o direito à identidade (SARLET; FERREIRA NETO, 2019, p. 67). Há também quem o extraia do direito à imagem (COLNAGO, 2019, p. 251) ou aponte tratar-se se um direito da personalidade autônomo (DINIZ, 2017, p. 20). Ainda, há quem garanta inexistir direito ao esquecimento, em um, mais ou em todos os sentidos que vem sendo desenvolvidos na doutrina (SARMENTO, 2016; BINENBOJM, 2014).

O que se pretende, nessa oportunidade, é desenvolver um esforço conceitual, para o qual será útil compreender como esse direito é entendido nos Estados Unidos e na Europa. A estratégia conceitual se desenvolverá da seguinte maneira: inicialmente se analisará a ideia de direito à privacidade, majoritariamente apontado como seu fundamento, e, a partir daí, os demais direitos correlatos poderão ser clarificados.

O direito à privacidade foi formulado pelos americanos Samuel D. Warren e Louis D. Brandeis, no final do século XIX. Warren e Brandeis foram colegas na Escola de Direito de Harvard, e cultivaram "uma amizade que transcendeu região, religião e classe" (RICHARDS, 2015, p. 16). Warren pertencia a uma família distinta; Brandeis era um judeu de classe média. Warren se casou com Mabel Bayard, que passou a se chamar Mabel Warren. A sra. Warren vinha de uma família rica, aristocrática e antissemita. Em razão da origem social dos Warren, o casamento foi amplamente noticiado e um fato chamou a atenção da imprensa: o sócio do noivo, Louis Brandeis, não foi convidado (RICHARDS, 2015, p. 16-17).

Nesse contexto, Warren e Brandeis escreveram o artigo The Right to Privacy, publicado na Harvard Law Review em 1890, defendendo a existência do direito à privacidade. Descrito como "o direito de uma pessoa "para decidir quanto conhecimento de seu pensamento e sentimento pessoal, e quanto conhecimento, portanto, de seus gostos e hábitos, de suas próprias ações e assuntos privados, e os de sua família sob o seu próprio teto, o público em geral deve ter"” (RICHARDS, 2015, p. 17) ${ }^{2}$, surgiu em razão de uma preocupação das elites de terem suas vidas escrutinadas pelas classes populares. A privacidade, nesse sentido, é um poder de impor à imprensa limites quanto à divulgação de fatos verdadeiros que dizem respeito à esfera pessoal de uma pessoa pública. Essa formulação inicial de

\footnotetext{
${ }^{2}$ Tradução nossa. No original: “[...] This was a person's right 'to decide how much knowledge of his personal thought and feeling, and how much knowledge, therefore, of his tastes and habits, of his own private doings and affairs, and those of his family living under his own roof, the public at large shall have"”.
} 
privacidade de Warren e Brandeis foi aos poucos rejeitada, à luz das teorias do autogoverno, da busca da verdade e da autorrealização individual (RICHARDS, 2015, p. 10).

A primeira se funda na necessidade de que cidadãos, para se autogovernarem, precisam ter contato com informações e opiniões compartilhadas por outros. Essa foi a formulação adotada por Brandeis (em um segundo momento da sua vida, no qual abandonou a teoria formulada em conjunto com Warren), e por Alexander Mieklejohn. Defende que a liberdade de expressão permite aos cidadãos tomar decisões inteligentes e informadas de autogoverno, não se tratando somente de um direito individual, mas de salvaguarda dos processos sociais da democracia (RICHARDS, 2015, p. 38-39).

A teoria da busca da verdade, defendida por Oliver Wendell Holmes e por John Milton (LARSON III, 2013, p. 17-19), tem em vista que frequentemente o ser humano está errado e é perigoso que juízes proíbam ideias que possam vir a ser consideradas verdadeiras no futuro. Assim, todos devem ter direito de acesso livre a um "mercado de ideias", pois a liberdade de expressão desimpedida é um bem público, que permite aos cidadãos avaliar e comparar ideias, crenças e suposições, trocando noções incorretas por outras melhores.

A terceira teoria, desenvolvida por Thomas Emerson e Edwin Baker, defende que a liberdade de expressão promove a autonomia individual e a autorrealização dos indivíduos, pois essa se dá com o desenvolvimento da mente, processo individual, influenciado, porém, pela relação do indivíduo com os outros componentes da sociedade. Assim, o indivíduo não é proprietário das informações sobre si, obtidas legalmente, compartilhadas publicamente, e que sejam importantes para que outros indivíduos ou a mídia desenvolvam suas potencialidades comunicativas (RICHARDS, 2015, p. 10).

A teoria da privacidade desenvolvida por Warren e Brandeis, repise-se, tinha em conta o universo das celebridades e visava cercear a imprensa. Porém, atualmente, nos Estados Unidos, à luz da Primeira Emenda ${ }^{3}$, as pessoas públicas não têm reconhecida tão ampla proteção do direito à privacidade, tendo em vista que o policiamento pelos tribunais sobre quais publicações são de legítima preocupação do público é tido como censura

\footnotetext{
3 "Congress shall make no law respecting an establishment of religion, or prohibiting the free exercise thereof; or abridging the freedom of speech, oro $\mathrm{f}$ the press; or the right of the people peaceably to assemble, and to petition the Government for a redress of grievances" (NATIONAL CONSTITUTION CENTER). Pode ser assim traduzida (tradução nossa): "O Congresso não fará nenhuma lei com respeito ao instituto da religião, ou proibindo seu livre exercício; ou restringindo a liberdade de expressão, ou da imprensa; ou o direito do povo de se reunir pacificamente e de fazer uma petição ao governo para reparação de queixas".
} 
(RICHARDS, 2015, p. 45-53). Atualmente, a liberdade de expressão é quase absoluta, com algumas exceções. A primeira é a divulgação de informações falsas, que não podem ocorrer, seja sobre figuras públicas, seja sobre pessoas comuns. Outra exceção é a informação que não é de legítimo interesse público, como a divulgação de vídeos de sexo explícito sem consentimento, ainda que de pessoas públicas. A terceira exceção diz respeito a informações obtidas ilegalmente e, por fim, a última diz respeito a interesses governamentais convincentes (RICHARDS, 2015, p. 60).

A palavra privacidade refere-se a publicações da imprensa e às leis que regulam dados pessoais. Nessas situações, aplicam-se as Fair Information Practices - FIP, um conjunto de princípios que regula as relações entre empresas e entidades governamentais que coletam, usam e divulgam informações pessoais sobre pessoas comuns ("titulares de dados") 4 . As FIPs foram cunhadas nos Estados Unidos na década de 1970 e têm o objetivo de garantir o processamento de dados de acordo com regras que informem aos titulares dos dados como estes são coletados e usados. As Diretrizes de Privacidade da OCDE e a Diretiva de Proteção de Dados da União Europeia de 1995 se basearam nas FIPs americanas (DONEDA, 2011, p. 1143-1144). Como esclarece Richards (2015, p. 75-76), as FIPs e os regulamentos acerca da proteção de dados pessoais não desafiam a Primeira Emenda.

$\mathrm{Na}$ matriz americana, o direito à privacidade está relacionado às ideias de liberdade, autonomia individual e proteção contra a intervenção do Estado na vida dos cidadãos (BYRUM, 2020, p. 104). Por outro lado, no direito europeu, a privacidade é entendida como um direito dignitário, uma forma de proteção à imagem, ao nome, e à reputação de uma pessoa e, assim, transfere-se o fardo do indivíduo para a sociedade, ou seja, a privacidade

\footnotetext{
4 São estes: (...) "1. Não deve haver sistemas de manutenção de registros de dados cuja própria existência seja secreta. 2. Deve haver uma maneira de um indivíduo descobrir quais informações sobre ele estão em um registro e como são usadas. 3. Deve haver uma maneira de um indivíduo evitar que informações obtidas sobre ele sejam usadas para um propósito ou feitas disponíveis para outros fins sem o seu consentimento. 4. Deve haver uma maneira de um indivíduo corrigir ou alterar um registro de dados pessoais identificáveis sobre ele. 5. Qualquer organização que cria, mantém, usa ou divulga registros de dados pessoais identificáveis deve assegurar a confiabilidade dos dados para o uso pretendido e deve tomar precauções razoáveis para evitar o uso indevido de dados." (RICHARDS, 2015, p. 73-74). Tradução pela autora. No original: "1. There must be no personal-data record-keeping systems whose very existence is secret. 2 . There must be a way for na individual to find out what information about him is in a record and how it is used. 3. There must be a way for na individual to prevent information about him obtained for one purpose from being use dor made available for other purposes without his consente. 4. There must be a way for na individual to correct or amend a recordo $f$ identifiable information about him. 5. Any organization creating, maintaining, using, or disseminating records of identifiable personal data must assure the reliability of the data for their intended use and must take reasonable precautions to prevent misuse of the data".
} 
deixa de ser um poder que pode ser exercido por um indivíduo e passa a ser um dever devido a essa pessoa por outros membros da sociedade (LARSON III, 2013, p. 10).

Em solo europeu, o direito dignitário de privacidade, concebido à maneira WarrenBrandeis, foi bastante desenvolvido pela doutrina alemã, na qual foi aos poucos foi identificado com a ideia autodeterminação informativa, que, para Larson III (2013, p. 10-11), "é um conceito do direito constitucional alemão que estabelece o direito do indivíduo de decidir como se retrata perante terceiros ou o público, se e em que medida as informações sobre o indivíduo são disponibilizadas a terceiros",

A ideia de privacidade como autodeterminação informativa influenciou a regulação de proteção de dados pessoais na Europa. Na Diretiva Geral no 95/46 da União Europeia, o direito ao esquecimento referia-se ao direito dos indivíduos de que cessar ou eliminar o processamento de dados quando estes (i) deixarem de ser necessários para fins legítimos, ou seja, para as finalidades para as quais os dados foram coletados, ou (ii) quando o titular dos dados retira o consentimento para o processamento de dados (TERWANGNE, 2014, p. 83).

No entanto, essa ideia se radicalizou. O direito ao esquecimento passou a ser interpretado como o direito de exigir que sites removam notícias que contenham informações de interesse público que, pela passagem do tempo, teriam se tornado de relevância unicamente privada, ou que motores de busca, como Google e Yahoo! desindexem esse tipo de notícia. Nesse sentido, o direito ao esquecimento é o direito de que sejam excluídas ou desindexadas informações verídicas, que concernem à esfera privada de alguém, mas que em algum momento também foi de interesse público, e das quais tal pessoa não deseja se lembrar. A ideia é de que uma informação de interesse privado e público pode perder essa última característica pelo mero transcurso do tempo (MALDONADO, 2017, p. 33).

Enquanto o primeiro sentido do direito ao esquecimento é aceito nos Estados Unidos como decorrência do direito à proteção de dados pessoais, o segundo sentido não é aceito como constitucional (RICHARDS, 2015, p. 75), pois "tornaria a web a nossa Wikipedia pessoal, nos dando o direito de editar dados sobre nós mesmos como nós gostamos" (RICHARDS, 2015, 75). Foi precisamente este o sentido adotado posteriormente no

5Tradução nossa. No original: "Informational self-determination is a concept from German constitucional law that establishes the right of the individual to decide how one will portray oneself to third parties or the public, and whether and to what extent information about the individual is made available to third parties". 
Regulamento Geral de Proteção de Dados da União Europeia (General Data Protection Regulation -GDPR) n 679, de 2016.

Conforme Ambrose e Ausloos (2013, p. 2; 14-15), o direito ao esquecimento surgiu na Europa como o reconhecimento, no âmbito criminal, do direito de um indivíduo que cumpriu uma sentença criminal deixar de ser associado às ações criminais. Posteriormente, surgiram duas outras interpretações. Os autores chamam a primeira de direito ao esquecimento (droit à l'oubli ou right to be forgotten), que abarca o direito de ser esquecido (direito de que terceiros esqueçam seu passado) e o direito ao esquecimento propriamente dito (direito de evitar ser confrontado com seu próprio passado). A segunda é chamada de direito ao apagamento (right to erasure), que permite ao titular de dados pessoais remover os dados que disponibilizou para processamento automatizado. Os autores esclarecem (2013, p. 16) que a "confusão conceitual" em torno do direito ao esquecimento foi, em boa parte, ocasionada pela fusão dos direitos ao esquecimento e ao apagamento no GDPR nº 679/2016 da União Europeia. Propõem que separar direito ao apagamento de direito ao esquecimento é um passo inicial importante para tratar dos temas, pois, enquanto o primeiro não é fruto de muito dissenso, o segundo o é (AMBROSE; AUSLOOS, 2013, p. 17-19).

Até o momento, foram clarificados alguns termos nebulosos, como direito à privacidade, direito à autodeterminação informacional e controle de dados pessoais. Falta, ainda, clarificar o que se entende por direitos à identidade e à imagem, com os quais alguns autores relacionam o direito ao esquecimento, embora se trate de uma posição minoritária.

Para Sarlet e Ferreira Neto (2019, p. 67-76), o direito à privacidade está relacionado com o direito à identidade e à imagem, os quais dependem de reconhecimento por parte de terceiros, que devem aceitar ou resguardar a construção ou reconstrução da imagem social do indivíduo. Concordando, expõe Andrade (2014, p. 67-68):

[...] $\mathrm{O}$ direito à identidade pode ser definido, de uma maneira muito básica, como o direito a ter seus indicia, atributos das facetas da personalidade que são característicos ou exclusivos de uma pessoa em particular (como aparência, nome, caráter, voz, história de vida e assim por diante) reconhecidos e respeitados por outros. [...]De acordo com esta conceptualização, a identidade de uma pessoa é violada se algum dos seus indícios for utilizado sem autorização de formas que não possam ser conciliadas com a identidade (e imagem social, projecção) que pretendem transmitir [...] (ANDRADE, 2014, p. 67-68)

\footnotetext{
${ }^{6}$ Tradução . No original: [...] The right to identity can be defined, in a very basic manner, as the right to have de indicia, atributes of the facets of personality witch are characteristic of, or unique to, a particular person (such as
} 
Não se pode esquecer, ainda, do posicionamento de Maria Helena Diniz (2017, p. 18 19), para quem o direito a ser esquecido é "um direito da personalidade, incluído na categoria do direito à integridade moral, tendo proteção própria”. Em sua visão, trata-se de um direito autônomo que integra o rol dos direitos da personalidade.

Antes de analisar a constitucionalidade do chamado direito ao esquecimento, é necessário clarificar a forma como serão adotados os conceitos desenvolvidos até aqui. Para isso, é imprescindível fazer escolhas, visto que, em se tratando de direitos fundamentais, os conceitos, limites e âmbito de proteção não são isentos de um olhar particular.

Sustenta-se que o "direito à privacidade" na matriz americana e na matriz europeia é o mesmo, trata-se do direito de uma pessoa de decidir quanto conhecimento de si quer que o público em geral tenha. A diferença se instala quanto a quem é possível opô-lo e qual o seu âmbito de proteção. Enquanto na matriz americana, trata-se de um direito oponível à imprensa e ao Estado, relacionado à autonomia individual e à liberdade, na matriz europeia, trata-se de um direito oponível a todos, relacionado à dignidade da pessoa humana. Na matriz americana tal direito abrange indivíduos não considerados pessoas públicas e unicamente quanto a fatos privados, aplicando-se excepcionalmente às pessoas públicas quanto a fatos muito ultrajantes. Já na matriz europeia, é aplicável indistintamente a todos os indivíduos, de maneira mais ampla. Nos Estados Unidos, a privacidade só é protegida à medida que não ameaçar a liberdade de expressão e de imprensa, isto é, a divulgação de informações verdadeiras, de interesse público e não ultrajantes, deve ser protegida, ainda que a autoimagem do indivíduo seja atingida. No Direito europeu, o direito à privacidade é associado com a autodeterminação informativa, podendo o indivíduo controlar qualquer informação privada que entenda ferir a sua imagem, nome e reputação, de acordo com a sua personalidade atual.

Em que pesem às diferenças apontadas, defende-se que não há oposição entre as ideias de autonomia individual e proteção contra a intervenção do Estado e a ideia de dignidade da pessoa humana. A autorrealização individual, chamada também de livre

appearance, name, character, voice, life history, and so on) recognised and respected by others. [...] According to this conceptualisation, a person's identity is infringed if any of his/her indicia are used without authorisation in ways which cannot be reconciled with the identity (and social image, projection) that they wished to convey. [...] (ANDRADE, 2014, p. 67-68) 
desenvolvimento da personalidade, é ínsita à formulação da dignidade humana (COSTA, 2011, p. 814-816). Tanto nos Estados Unidos quanto na Europa, o direito à privacidade tem raízes kantianas, na ideia de dignidade humana. Se não há diferenças quanto às raízes dignitárias do mesmo direito, a diferença encontra-se, na verdade, quanto à extensão do direito à privacidade, que, acredita-se, é mais sustentável em sua versão americana.

O direito à privacidade não conflita com a liberdade de expressão e o direito à informação, pois ambos têm diferentes âmbitos de cabimento. $\mathrm{O}$ direito à privacidade recai sobre fatos e assuntos privados, enquanto os direitos à informação e à liberdade de expressão recai sobre fatos e assuntos públicos e de interesse público. Adotando-se a teoria da unidade do valor de Dworkin, não há conflito entre esses direitos, pois ambos estão fundamentados no princípio da dignidade humana. O que pode haver, isso sim, é uma indefinição quanto ao que seja fatos e assuntos privados e fatos e assuntos públicos e de interesse público. Mas o que seriam fatos e assuntos privados? E como distinguir assunto privado de interesse público?

Uma teoria interessante para a compreensão das noções de privacidade e intimidade é a teoria das esferas, de Hubmann, proveniente do direito alemão. Essa vislumbra três esferas concêntricas na noção de privacidade, as esferas privada, íntima e secreta. A esfera do segredo é a esfera da intimidade, na qual o ser humano pode excluir do conhecimento de outros os aspectos mais íntimos da sua personalidade (PEIXOTO, 2017, p. 25). Por sua vez, a esfera privada diz respeito às relações que o homem possui na sua vida cotidiana, em círculos sociais pequenos, tais como na sua vida profissional, suas amizades e família (PEIXOTO, 2017, p. 25). Por fim, a esfera individual protege a vida do indivíduo nas suas relações com o mundo, ou seja, protege a individualidade do ser humano enquanto membro da sociedade. Trata-se do âmbito "mais afastado do núcleo e já na fronteira entre o privado e o público, [em que] o indivíduo tem uma abertura maior, se relacionando com o mundo como ser social que é, mas ainda mantendo sua individualidade" (PEIXOTO, 2017, p. 25). A intensidade da tutela jurídica será maior quando a violação se der na esfera do segredo e paulatinamente menor quando ocorrer nas esferas privada e individual.

O modelo das esferas influenciou bastante a doutrina brasileira que trata dos direitos à intimidade e vida privada, sendo adotada por Paulo Lôbo, Danilo Doneda, Roxana Borges, Antônio Jeová dos Santos, José Afonso da Silva, dentre outros (PEIXOTO, 2017, p. 24-25). No entanto, vem sendo criticada, mediante o argumento de ser difícil distinguir as situações 
correspondentes às esferas desenhadas. Alguns autores, como Peixoto (2017) e Cancelier (2017) procuram teorias alternativas para a compreensão do direito à privacidade.

Para Cancelier (2017, p.p. 225-229), a noção de privacidade deve ser fluida, sendo melhor compreendida não a partir de quais esferas da vida das pessoas devem ser abrigadas da curiosidade alheia, mas em quais situações/contextos deve a privacidade ser reconhecida. $\mathrm{O}$ direito à privacidade, em um mundo digitalizado, pode ser reconhecida mesmo em um ato praticado publicamente, como no caso de divulgação de vídeos íntimos ocorridos no caso de porn revenge, pois, mesmo havendo limitação voluntária do exercício da privacidade, não se pode retirar da vítima a tutela jurídica (CANCELIER, 2017, p. 232).

Nesse palmilhar, Cancelier (2017) aduz que a natureza privada de um determinado fato deve ser aferida conforme o contexto em que praticado. O autor tem razão ao apontar para a importância do contexto, ao se aferir quando uma determinada situação é privada ou pública e de interesse público. De fato, não há como entender como sendo pública a filmagem de relações sexuais, ocorrida em local privado, praticada por duas pessoas em situação de intimidade e com a mútua confiança de que não haveria posterior divulgação. Trata-se de uma situação relacionada ao direito à privacidade, mesmo que haja posterior divulgação para o público. Importa a expectativa que os envolvidos têm a respeito daquela situação e, nos casos de porn revenge, a expectativa é de que o fato permaneça na esfera privada. Nesse ponto, importante distinguir informação pública de informação de interesse público. Somente estão protegidas no âmbito da liberdade de expressão e do direito à informação informações públicas verídicas de interesse público. Informações que foram publicizadas de modo a ferir o direito à privacidade não estão protegidas pela liberdade de expressão.

Cabe salientar, outrossim, que reconhecer a importância do contexto não significa, por outro lado, deixar a definição de fato privado ao alvedrio do interessado no seu reconhecimento. Os critérios para isso não podem ser tão subjetivos. É importante existirem elementos objetivos para classificar determinado fato como privado, como, por exemplo, considerando o local onde ocorreu (a casa do indivíduo, por exemplo), e a expectativa de privacidade em torno do ato praticado (CANCELIER, 2017, p. 224-229). Ademais, deve-se reconhecer que às pessoas públicas só se deve reconhecer o direito à privacidade notadamente quanto a atos praticados em público - de forma excepcional, em situações que se afigurem ultrajantes. 
Enquanto Cancelier (2017) enfoca sua análise no aspecto contextual da privacidade, Peixoto (2017) propõe a reformulação da teoria das esferas, salientando que, a depender da situação concreta, uma informação que inicialmente compunha a esfera do segredo pode passar à esfera privada e vice-versa; ou seja, aduz que as esferas são permeáveis.

Analisando-se ambos os modelos, vê-se que apresentam dificuldades em igual medida, quanto à classificação dos fatos como privados ou públicos. Logo, não procede a crítica ao modelo das esferas, pois a dificuldade é paritária: em ambos os modelos, é necessário um exercício hermenêutico e interpretativo para classificar fatos ou assuntos como privados ou como públicos - o que difere são os critérios para tanto. Entende-se como útil a distinção apresentada por Hubmann entre as esferas secreta, privada e individual, pois oferece um critério seguro para analisar as situações que clamam a proteção do direito à privacidade. Se é admissível o apontamento de Cancelier (2017), de que o contexto importa para definir um fato ou situação como privada ou como pública, por outro lado, a admissão do modelo permeável como alternativa ao modelo das esferas é problemática. Isso porque tal modelo contém, implicitamente, uma suposição: a de que uma informação inicialmente de interesse público poderia, com a passagem do tempo, vir a ser de interesse exclusivamente privado ou mesmo íntimo. A suposição é problemática, pois desconsidera o direito à memória, individual e coletiva.

Entende-se que, no caso de informação pública e de interesse público, não há a perda do interesse público pela mera passagem do tempo. Nesse particular, concorda-se com Sarmento (2016, p. 193) no sentido de que essa ideia se tornaria um remédio jurídico tomado por poderosos de todo tipo com intuito de apagar registros históricos sobre seus passados. Além disso, o direito à informação é essencial para o livre desenvolvimento da pessoa humana, porque facilita o desenvolvimento da personalidade, verdadeiro pressuposto para o exercício dos demais direitos.

Enquanto o direito à privacidade está relacionado a tudo quanto englobe a esfera privada do indivíduo, o direito à informação e à liberdade de expressão engloba tudo quanto represente um interesse público, e este deve ser interpretado de forma alargada. É de interesse público a atividade política, a atuação dos poderes públicos e seus agentes, mas também outros temas menos óbvios, como costumes, criminalidade, práticas e relações sociais, mentalidades, economia, entre outros (SARMENTO, 2016, p. 197). Para que o interesse 
público seja atendido, o direito à privacidade não pode ser igualado ao direito à autodeterminação informativa.

O direito à autodeterminação informativa é entendido como o direito que alguém tem de estabelecer como deve ser retratado perante terceiros e perante o público em geral. Essa definição, sobremodo ampla, acaba por transformar qualquer espaço público (imprensa, internet, etc.), para usar uma expressão de Richards (2015, p. 75) na "wikipedia pessoal” de cada um. Embora se reconheça que o ser humano é um ser mutável, é perigoso exigir que seja sempre retratado de acordo com a personalidade, nome e imagem que o indivíduo tem de si mesmo na atualidade. Não se pode condicionar a disseminação de informações de interesse público ao subjetivismo do indivíduo, do mesmo modo que não se pode reduzir a hermenêutica jurídica à discricionariedade (STRECK, 2017). Ademais, qualquer mudança na identidade individual sempre implica certa permanência, sendo o passado um componente inafastável da personalidade do indivíduo, e que não pode ser escondido ao seu bel prazer. $\mathrm{O}$ direito à privacidade, sob essa luz, nada tem que ver com o direito à autodeterminação informativa, nem mesmo com o chamado direito ao esquecimento. Apesar das vozes majoritárias que derivam o direito ao esquecimento do direito à privacidade, entende-se que não há correlação entre ambos.

Defende-se, outrossim, que o direito à autodeterminação informativa não se confunde com o direito à proteção e ao controle de dados pessoais. Este envolve o poder do indivíduo de controlar os usos de seus dados fornecidos ou coletados para processamento de informações valiosas para terceiros, e é muito menos amplo que o direito à autodeterminação informativa, que envolve o direito de alguém dizer como deve ser retratado perante terceiros. $\mathrm{Na}$ Europa, o direito ao controle de dados pessoais foi chamado droit à l'oubli ou right to be forgotten, porém, essa não é a melhor terminologia. A melhor terminologia é a defendida por Ausloos e Ambrose (2013), a saber, direito ao apagamento, que se diferencia do direito ao esquecimento. Assim, o direito à autodeterminação informacional só pode ser admitido se restrito aos limites do direito à proteção e ao controle dos dados pessoais.

Cabe, por fim, circunscrever aquilo que se entende por direito ao esquecimento. Comumente, este é apontado em um sentido amplo, que envolve (1) o direito à proteção e controle de dados pessoais (direito ao apagamento), (2) o direito à desindexação e (3) o direito do indivíduo de que sejam excluídas informações verídicas, das quais não deseja se lembrar, 
informações essas que já foram de interesse público e passaram a ser, pela passagem do tempo, de interesse exclusivamente privado. A seguir, se buscará examinar a constitucionalidade do direito ao esquecimento nos sentidos apontados.

\section{A CONSTITUCIONALIDADE DO DIREITO AO ESQUECIMENTO À LUZ DA TEORIA INTERPRETATIVA DE RONALD DWORKIN.}

Estudaram-se os conceitos de direitos fundamentais relacionados com o chamado direito ao esquecimento, a saber, direitos à privacidade, à imagem, à autodeterminação informativa, ao controle de informações e dados pessoais. Assim, se chegou a um conceito amplo de direito ao esquecimento, defendido por boa parte da doutrina, que envolve (1) o direito à proteção e controle de dados pessoais (direito ao apagamento), (2) direito à desindexação e (3) direito amplo do indivíduo de que sejam excluídas informações verídicas, das quais não deseja se lembrar, informações essas que já foram de interesse público e passaram a ser, pela passagem do tempo, de interesse exclusivamente privado.

A semelhança entre todos os direitos apontados acima é o seu fundamento no princípio da dignidade da pessoa humana. Essa, por sua vez, deve ser compreendida não só à luz do valor intrínseco do ser humano (dimensão individual), mas também da responsabilidade pessoal de cada um por seus atos (dimensão social). Tendo em vista esse pressuposto, devem os direitos relacionados acima ser interpretados de forma que todos se harmonizem entre si, à luz do princípio que os sustenta. Isto é, esses direitos não entram em conflito, pois têm âmbitos de aplicabilidade diferentes, e, apesar disso, garantem igualmente a dignidade humana. Não se pode entender a dignidade da pessoa humana unicamente de uma maneira subjetivista e individual, como o direito de cada um de impor a outros a forma como pretende ser retratado, por exemplo; não se pode entender a dignidade da pessoa humana como fundamento para extirpar a responsabilidade pessoal; e certamente não se pode entender a dignidade humana como fundamento para que atos cometidos no passado, públicos e de interesse público, sejam extirpados do conhecimento público, pois o direito à memória individual e coletiva - e o direito de cada um de ter acesso a determinadas informações e assim moldar o seu eu, também faz parte do que se compreende por dignidade humana. 
Não obstante a dificuldade de se conceituar dignidade humana, acredita-se que Dworkin dá uma visão bastante clara do que essa ideia significa. A dignidade é a qualidade da pessoa a impor que nenhum ser humano possa ser coisificado ou instrumentalizado. Contudo, não tem um espectro apenas individual, visto que as pessoas nascem, vivem e morrem em uma sociedade; portanto, há a dimensão social e relacional da dignidade humana, uma dimensão intersubjetiva, que deve ser avaliada (GAMA, 2011, p. 256). O limite do direito à privacidade e do direito à "autodeterminação informacional" é a liberdade de autorrealização dos demais indivíduos, que, para moldarem seu eu, devem ter livre e amplo acesso a informações de interesse público. Todos esses direitos estão assegurados pelo princípio da dignidade humana e são passíveis de conciliação. Essa não é uma ideia nova, pelo contrário, é algo assaz corriqueira:

O tema envolvendo a dignidade da pessoa humana e as relações intersubjetivas
conduz à polêmica quanto à instauração de um conflito entre as dignidades de
pessoas diferentes [...] Por óbvio que, neste caso extremo, a dignidade da pessoa
humana relativamente a um dos envolvidos - ou quiçá de ambos - deverá ser
relativizada, dentro de um juízo de valor realizado no caso concreto, o que denota o
princípio (e não o valor) da dignidade da pessoa humana não é absoluto,
diversamente do que alguns apregoam. A segregação do criminoso ao cárcere, diante
de uma condenação por infração grave, demonstra a efetiva atuação estatal no
sentido de proteger a dignidade dos particulares que devem ter sua vida, liberdade e
dignidade protegidas, o que não ocorreria caso a pessoa que delinquiu gravemente
não fosse sancionada com a medida mais extrema de privação da liberdade [...]
(GAMA, 2011, p. 264-265)

Na verdade, não há relativização da dignidade humana: há a interpretação dos diversos direitos abarcados sob essa ideia de forma harmônica. O problema da formulação europeia do direito ao esquecimento como autodeterminação informacional é o de não realizar praticamente essa harmonização, mas de enxergar um conflito entre privacidade e liberdade de expressão, e tratar o primeiro como prioritário (DE BAETS, 2016, p. 2).

Destaque-se que, nesse particular, não há qualquer legislação no Brasil tratando do direito ao esquecimento nos sentidos de direito à desindexação e direito a excluir do conhecimento do público fatos passados de interesse público; por essa razão, a doutrina comumente aponta que o direito ao esquecimento se trataria de um direito constitucional implícito. Embora se admita, de fato, a existência de direitos constitucionais implícitos - ideia defendida, inclusive, por Dworkin - vê-se que a defesa de um direito à desindexação e de excluir do conhecimento dos outros informações de interesse público não tem fulcro no 
princípio da dignidade humana, analisados os demais direitos originários dessa ideia. Por outro lado, essas duas formulações do direito ao esquecimento se equivalem: o direito de desindexar determinada informação de um domínio na internet nada mais é que a de excluir do conhecimento do público fatos de interesse público. A internet é, hoje, o principal meio de comunicação e informação. Não se assinam mais jornais e revistas, não se frequentam mais bibliotecas como outrora. As informações são buscadas na internet e limitar a busca a palavras-chave que possam levar à informação de interesse público nada mais é que censura.

Cabe salientar que, até o momento, buscaram-se as raízes do chamado direito ao esquecimento no princípio da dignidade humana, que, no Brasil, foi elevado a fundamento do Estado Democrático de Direito (art. $1^{\text {o }}$, III, da Constituição da República). Mas isso, por si só, não é suficiente para propor a interpretação acima construída. Seguindo os passos de Dworkin, não basta interpretar os princípios mais genéricos e gerais da ordem constitucional, mas deve-se também buscar a interpretação dos Tribunais, das leis mais concretas, dos preceitos legais.

Trabalhos científicos de peso revelam a completa ausência de parâmetros jurisprudenciais, no Brasil, para decisão de questões relativas ao direito à liberdade de expressão (LEITE; HANNIKAINEN; NHUCH, 2016; HARTMANN, 2020). Enquanto no STJ parece haver posicionamento que dá prioridade ao direito à honra sobre o direito à liberdade de expressão (MELLO, 2016, p. 22) e uma tendência a adotar o direito ao esquecimento nos três sentidos mencionados, o STF já salientou, nos autos da ADI 4.815, Rel. Min. Carmen Lúcia, j. em 10/06/2015 (conhecido caso das autobiografias não autorizadas), que a liberdade de expressão no estado brasileiro goza de uma posição preferencial dentro do ordenamento jurídico. Recentemente, o STF deu um passo maior no reconhecimento da importância da liberdade de expressão e afastamento da ideia de direito ao esquecimento em casos públicos e de interesse público. Com efeito, ao votar, no mês de fevereiro do corrente ano de 2021, o RE 1.010.606/RJ, de relatoria do Min. Dias Toffoli, em sede de repercussão geral, o Supremo firmou a seguinte tese:

É incompatível com a Constituição a ideia de um direito ao esquecimento, assim entendido como o poder de obstar, em razão da passagem do tempo, a divulgação de fatos ou dados verídicos e licitamente obtidos e publicados em meios de comunicação social analógicos ou digitais.

Eventuais excessos ou abusos no exercício da liberdade de expressão e informação devem ser analisados caso a caso, a partir dos parâmetros constitucionais - 
especialmente os relativos à proteção da honra, da imagem, da privacidade e da personalidade em geral - e as expressas e específicas previsões legais nos âmbitos penal e cível ${ }^{7}$.

A decisão ainda é recente, mas se mostra um grande avanço no sentido que ora se defende. Resta acompanhar se, no futuro, as "exceções" citadas pelo STF se tornaram ou não regras, e como serão interpretadas. Ainda se pode dizer que o estudo da jurisprudência no Brasil não se afigura um critério muito preciso para elaborar qualquer tese plausível, dada a alta carga de subjetivismo dos julgadores, num verdadeiro estado de exceção hermenêutico no qual predomina o império da discricionariedade (ZANIN, 2020).

Por esse viés, é que se defende que o direito ao esquecimento só pode ser considerado constitucional, no Brasil, se identificado com o direito à proteção e controle de dados pessoais (direito ao apagamento). Somente por esse viés é que o direito ao esquecimento não malfere o princípio que o sustenta, qual seja, o da dignidade humana, e se harmoniza com os demais direitos com os quais se relaciona. $\mathrm{O}$ direito ao controle de dados pessoais se trata do direito do indivíduo de retirar o consentimento para uso e processamento de dados pessoais que o próprio forneceu no passado, e é garantido no Brasil, atualmente, pela Lei ${ }^{\circ} 13.709$, de 2018. Noutra senda, o direito à desindexação - consistente na desvinculação de uma notícia verdadeira, de interesse público, de mecanismos de busca na internet - e o direito mais amplo de excluir informações verídicas, das quais o indivíduo não deseja se lembrar, não coaduna com a estrutura principiológica brasileira - e nem mesmo com a mais recente jurisprudência do STF.

\section{CONSIDERAÇÕES FINAIS}

A pesquisa ora desenvolvida buscou analisar a constitucionalidade dos vários sentidos atribuídos à expressão direito ao esquecimento, à luz da teoria interpretativa de Ronald Dworkin. Para tanto, procurou-se clarificar conceitos relacionados comumente ao direito ao esquecimento, como direitos à privacidade, à identidade, à autodeterminação informacional e ao controle de dados. Após, buscou-se demonstrar como a ideia de

\footnotetext{
${ }^{7} \mathrm{O}$ acórdão não foi publicado até a data do envio deste artigo para avaliação, porém, é possível consultar o resultado do julgamento na aba "andamentos" da consulta pública ao mencionado recurso extraordinário.
} 
privacidade pode ser conciliada a liberdade de expressão, resultando que não necessariamente sejam ideias opostas, à luz do princípio da dignidade humana. Para isso, foi útil a teoria de Ronald Dworkin que defende a teoria da unidade do valor: não há oposição entre esses direitos, os quais podem ser conciliados, se se pensar na dignidade da pessoa humana como um princípio que os abarca de maneira igual.

Após diferenciar três sentidos nos quais o direito ao esquecimento é compreendido, chegou-se à conclusão de que este só pode ser entendido como constitucional, no Brasil, se identificado com o direito ao controle de dados pessoais. Por outro lado, não se pode entender como constitucional o direito ao esquecimento se este for identificado com o direito de um indivíduo de excluir ou desindexar informações sobre si que entenda serem vexatórias e prejudiciais à sua imagem e identidade, ainda que essas informações sejam de interesse público. É que não se admite que uma informação de interesse público perca, com a passagem do tempo, importância para a memória, individual ou coletiva. Existe um direito à memória, relacionado com o direito à autorrealização do indivíduo e com a dignidade humana, que não pode estar subordinado a subjetivismos individuais (dimensão individual). Por outro lado, a dignidade humana não pode ser entendida sob a perspectiva meramente individualista, mas deve ser compreendida na perspectiva relacional (dimensão social).

O projeto de interpretação do direito ao esquecimento à luz da teoria de Ronald Dworkin, no entanto, só foi realizado de forma parcial. Está longe de englobar a análise de todas as questões relevantes para o desenrolar do tema - por exemplo, ficou de fora qualquer reflexão sobre a legislação de proteção do direito à honra no Brasil. Reflexões mais acuradas sobre a Lei Geral de Proteção de Dados também foram postergadas para outra ocasião. Assim, confessa-se que longe está esse projeto de ser a análise do Juiz Hércules imaginado por Dworkin. Porém, entende-se que, pelo menos de forma parcial, os objetivos propostos foram atingidos.

\section{REFERÊNCIAS}

AMBROSE, Meg Leta; AUSLOOS, Jef. The right to be forgotten across the pond. Journal of information policy 3 (2013), p. 1-23. Disponível em

https://www.jstor.org/stable/10.5325/jinfopoli.3.2013.0001. Acesso em 30 out. 2020. 
ANDRADE, Norberto Nuno Gomes de. Oblivion: the right to be different...from oneself: reproposing the right to be forgotten. In: GHEZZI, Alessia (et al.). The ethics of memory in a digital age: interrogating the right to be forgotten. Basingstoke-England, 2014.

BINENBOJM, Gustavo. Direito ao esquecimento: a censura no retrovisor. OS CONSTITUCIONALISTAS: um blog para pensar, desconstruir e revolucionar o Direito Constitucional, 2014. Disponível em: https://www.osconstitucionalistas.com.br/direito-aoesquecimento-a-censura-no-retrovisor. Acesso em: 24 out. 2019.

BYRUM, Kristie. The european right to be forgotten: a challenge to the United States Constitution's First Amendment and to professional public relations ethics. Public Relations Review 43 (2017), p. 102-111.

CANCELIER, Mikhail Vieira de Lorenzi. O Direito à Privacidade hoje: perspectiva histórica e o cenário brasileiro. Sequência, Florianópolis, n. 76, p. 213-240, ago. 2017.

COELHO, Inocêncio Mártires. Da hermenêutica filosófica à hermenêutica jurídica. $2^{\mathrm{a}}$ ed. São Paulo: Saraiva, 2014.

COLNAGO, Cláudio de Oliveira Santos. Liberdade de expressão na internet. Salvador: Juspodivm, 2019.

COSTA, Judith Martins. Livre desenvolvimento da personalidade. In: TORRES, Ricardo Lobo; KATAOKA, Eduardo Takemi; GALDINO, Flavio (orgs.). Dicionário de princípios jurídicos. Rio de Janeiro: Elsevier, 2011, pp. 813-833.

DALL'AGNOL, Darlei. O igualitarismo liberal de Dworkin. Kriterion, Belo Horizonte, n. 111, jun/2005, p. 55-69.

DE BAETS, Antoon. A historian's view on the right to be forgotten. International Review of Law, Computers \& Technology. Vol. 30, 2016.

DINIZ, Maria Helena. Efetividade do direito a ser esquecido. Revista Argumentum, Marília/SP, v. 18, n. 1, pp. 17-41, jan-abr. 2017, p. 20.

DONEDA, Danilo. Proteção de dados pessoais. In: TORRES, Ricardo Lobo; KATAOKA, Eduardo Takemi; GALDINO, Flavio (orgs.). Dicionário de princípios jurídicos. Rio de Janeiro: Elsevier, 2011, pp. 1.141-1.148.

DWORKIN, Ronald. Uma questão de princípio. 2 ed. São Paulo: Martins Fontes, 2005.

. Levando os direitos a sério. São Paulo: Martins Fontes, 2010.

GAMA, Guilherme C. Nogueira da. Dignidade humana (no Biodireito). In: TORRES, Ricardo Lobo; KATAOKA, Eduardo Takemi; GALDINO, Flavio (orgs.). Dicionário de princípios jurídicos. Rio de Janeiro: Elsevier, 2011, pp. 252-272. 
HARTMANN, Ivar A. Crise dos precedentes no Supremo: o caso dos precedentes sobre liberdade de expressão. Revista Estudos Institucionais, v. 6, n. 1, p. 109-128, jan./abr. 2020.

FADEI, Anna Laura Maneschy; VERBICARO, Loiane Prado. O modelo de democracia à luz da teoria de Ronald Dworkin. Revista Jurídica, vol. 03, n. 52, Curitiba, 2018, p. 248-274.

JUNG, Luã Nogueira. A filosofia política de Ronald Dworkin: objetividade moral, liberalismo político e crítica comunitarista ao atomismo liberal. Revista intuitio. Porto Alegre, vol. 9, n. 1, jul./2016, p. 111-130.

LARSON III, Robert G. Forguetting the first amendment: how obscurity-based privacy and a right to be forgotten are incompatible with free speech. Journal Communication Law and Policy. Volume 18, 2013, issue 1.

LEITE, Fábio Carvalho; HANNIKAINEN, Ivar Allan Rodriguez; NHUCH, Flavia Kamenetz. Adivinhe quem vem para jantar. A liberdade de expressão do ofensor e o subjetivismo do julgador na análise dos crimes de injúria. Revista da Faculdade de Direito -UFPR, Curitiba, vol. 61, n. 3, set./dez. 2016, p. 259-276.

LUCENA, Marina Giovanetti Lili. A tutela jurídica do direito ao esquecimento no Brasil: conceito e aplicação no STJ e STF. (Dissertação de Mestrado). Programa de Pós-Graduação em Direito e Inovação. Universidade Federal de Juiz de Fora, 2018.

LUZ, Thiago dos Santos. O direito como ramo da moral política e o STF. Boletim Científico ESMPU, Brasília, a. 15 -n. 47, p. 213-249, jan./jun. 2016. Disponível em:

http://escola.mpu.mp.br/publicacoes/boletim-cientifico/edicoes-do-boletim/boletim-cientificon-47-janeiro-junho-2016/o-direito-como-ramo-da-moral-politica-e-o-stf. Acesso em 17 out. 2020.

MALDONADO, Viviane Nóbrega. Direito ao esquecimento. Barueri-SP: Novo Século Editora, 2017.

MELLO, Rodrigo Gaspar de. Liberdade de expressão, honra e responsabilidade civil. (Tese de doutorado). Programa de Pós-Graduação em Direito. Pontifícia Universidade Católica do Rio de Janeiro, 2016.

NATIONAL CONSTITUTION CENTER. First amendment: freedom of religion, speech, press, assembly, and petition. Disponível em: https://constitutioncenter.org/interactiveconstitution/amendment/amendment-

i\#: :text=Congress\%20shall\%20make\%20no\%20law,for\%20a\%20redress\%20of\%20grievance s. Acesso em 28 fev. 2021.

PEIXOTO, Erick Lucena. O conteúdo do direito da privacidade no direito brasileiro contemporâneo. Dissertação (Mestrado em Direito). Universidade Federal de Alagoas. Maceió, 2017. 
RICHARDS, Neil. Intellectual privacy: rethinking civil liberties in the digital age. New York: Oxford University Press, 2015.

SARLET, Ingo Wolfgang; FERREIRA NETO, Arthur M. O direito ao "esquecimento" na sociedade da informação. Porto Alegre: Livraria do Advogado, 2019.

SARMENTO, Daniel. Liberdades comunicativas e "direito ao esquecimento" na ordem constitucional brasileira. Revista Brasileira de Direito Civil, vol. 7, jan-mar. 2016.

STRECK, Lenio Luiz. Verdade e consenso: constituição, hermenêutica e teorias discursivas. 4.ed. São Paulo: Saraiva, 2017.

SUPREMO TRIBUNAL FEDERAL. Recurso Extraordinário 1.010.606/RJ. Julgado em 11/02/2021, Relator Dias Toffoli.

TERWANGNE, Cécile de. The right to be forgotten and informational autonomy in the digital enviroment. In: GHEZZI, Alessia (et al.). The ethics of memory in a digital age: interrogating the right to be forgotten. Basingstoke-England, 2014.

THEODORO FILHO, Wilson Roberto. A teoria da interpretação em Ronald Dworkin. Revista Jurídica da Presidência. Brasília, v. 17, n. 113, out. 2015/jan. 2016, p. 657-676.

ZANIN, Fabrício Carlos. Hermes no limbo: a hermenêutica jurídica entre exceção e aplicação. Revista de Argumentação e Hermenêutica Jurídica. v. 6, n. 1, jan./jun, 2020, p. 37 59. Disponível em:

https://www.indexlaw.org/index.php/HermeneuticaJuridica/issue/view/515. Acesso em 15 out. 2020. 